\title{
Laboratory Test Baseline Flag
}

National Cancer Institute

\section{Source}

National Cancer Institute. Laboratory Test Baseline Flag. NCI Thesaurus. Code C83303.

An indication or description that laboratory test data is a baseline value. 